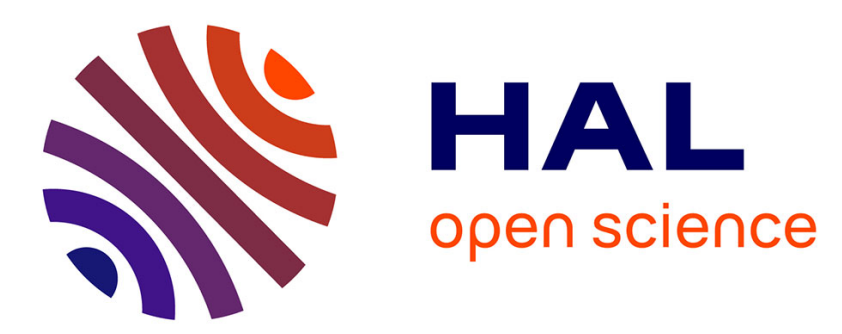

\title{
Effect of pathogenic mutations on the structure and dynamics of Alzheimer's A $\beta$-amyloid oligomers
}

Kristin Kassler, Anselm H. C. Horn, Heinrich Sticht

\section{To cite this version:}

Kristin Kassler, Anselm H. C. Horn, Heinrich Sticht. Effect of pathogenic mutations on the structure and dynamics of Alzheimer's A $\beta$-amyloid oligomers. Journal of Molecular Modeling, 2009, 16 (5), pp.1011-1020. 10.1007/s00894-009-0611-1 . hal-00568331

\section{HAL Id: hal-00568331 https://hal.science/hal-00568331}

Submitted on 23 Feb 2011

HAL is a multi-disciplinary open access archive for the deposit and dissemination of scientific research documents, whether they are published or not. The documents may come from teaching and research institutions in France or abroad, or from public or private research centers.
L'archive ouverte pluridisciplinaire HAL, est destinée au dépôt et à la diffusion de documents scientifiques de niveau recherche, publiés ou non, émanant des établissements d'enseignement et de recherche français ou étrangers, des laboratoires publics ou privés. 


\section{Editorial Manager(tm) for Journal of Molecular Modeling Manuscript Draft}

Manuscript Number: JMM0970

Title: Effect of Pathogenic Mutations on the Structure and Dynamics of Alzheimer's A 342 -Amyloid Oligomers

Article Type: Original paper

Keywords: molecular dynamics; energetic analysis; protein interaction; oligomerization; fibrillation; glutamate 22

Corresponding Author: Prof. Heinrich Sticht,

Corresponding Author's Institution:

First Author: Kristin Kassler

Order of Authors: Kristin Kassler; Anselm H Horn; Heinrich Sticht

Abstract: Converging lines of evidence suggest that soluble $A \beta$-amyloid oligomers play a pivotal role in the pathogenesis of Alzheimer's disease, and present direct effectors of synaptic and cognitive dysfunction. The three pathological E22-A 3 -amyloid point mutants (E22G, E22K, E22Q) and the deletion mutant E22 $\Delta$ exhibit an enhanced tendency to form prefibrillar aggregates. The present study assessed the effect of these four mutations from molecular dynamics simulations and subsequent structural and energetic analyses. Our data shows that E22 plays a unique role in wild type $A \beta$, since it has a destabilizing effect on the oligomer structure due to electrostatic repulsion between adjacent E22 side chains. Mutations, which replace E22 by an uncharged residue, consequently result in higher oligomer stability. This effect is also observed to a lesser extent for the E22K mutation and is consistent with the lower pathogenicity compared to other mutants. Interestingly, the deletion of E22 does not destroy the amyloid fold but is compensated by local changes of the backbone geometry, which allow the preservation of a structurally important salt bridge. The finding that all mutant oligomers investigated exhibit a higher internal stability than the wild type offers an explanation for the experimentally observed enhanced oligomer formation and stability. 


\title{
Effect of pathogenic mutations on the structure and dynamics of
} Alzheimer's A $\boldsymbol{\beta}_{42}$-amyloid oligomers

\section{Received: 17.08.2009 / Accepted:}

\author{
Kristin Kassler ${ }^{1}$, Anselm H. C. Horn ${ }^{1}$, Heinrich Sticht ${ }^{1, \bigotimes}$ \\ ${ }^{1}$ Bioinformatik, Institut für Biochemie, Friedrich-Alexander-Universität Erlangen-Nürnberg, \\ Fahrstraße 17, 91054 Erlangen, Germany \\ ${ }^{\circledR}$ Tel.: +49-9131-8524614, Fax: +49-9131-8522485; E-mail: H.Sticht@ biochem.uni- \\ erlangen.de
}

\begin{abstract}
Converging lines of evidence suggest that soluble $A \beta$-amyloid oligomers play a pivotal role in the pathogenesis of Alzheimer's disease, and present direct effectors of synaptic and cognitive dysfunction. The three pathological E22-A $\beta$-amyloid point mutants (E22G, E22K, E22Q) and the deletion mutant E22 $\Delta$ exhibit an enhanced tendency to form prefibrillar aggregates. The present study assessed the effect of these four mutations from molecular dynamics simulations and subsequent structural and energetic analyses. Our data shows that E22 plays a unique role in wild type $A \beta$, since it has a destabilizing effect on the oligomer structure due to electrostatic repulsion between adjacent E22 side chains. Mutations, which replace E22 by an uncharged residue, consequently result in higher oligomer stability. This effect is also observed to a lesser extent for the E22K mutation and is consistent with the lower pathogenicity compared to other mutants. Interestingly, the deletion of E22 does not destroy the amyloid fold but is compensated by local changes of the backbone geometry, which allow the preservation of a structurally important salt bridge. The finding that all mutant oligomers investigated exhibit a higher internal stability than the wild type offers an explanation for the experimentally observed enhanced oligomer formation and stability.
\end{abstract}

Keywords Molecular dynamics - Energetic analysis • Protein interaction • Oligomerization $\cdot$ Fibrillation $\cdot$ Glutamate 22 


\section{Introduction}

When the physician Alois Alzheimer spotted a rare case of progressive dementia in 1906 [1], he could not presage that 100 years later that disease would be one of the most severe health problems of the world's industrial nations. Persons with Alzheimer's disease (AD) suffer from a progressive decline of memory and cognitition, resulting from the dysfunction or loss of neurons [2,3]. One of the most prominent cytopathological hallmarks of AD affected tissue is the growing number of fibrillar plaques composed of abnormally altered and aggregated $A \beta$-amyloid protein, which is a cleavage product of the amyloid precursor protein (APP) [4]. Although two pathological $A \beta$-amyloid isoforms, $A \beta_{42}$ and $A \beta_{40}$, are known, the 42 amino acid long peptide appears to be the more disease relevant species [5]. The deposition of $\mathrm{A} \beta$-fibrils into plaques is preceded by an aggregation pathway involving several intermediate states such as oligomers and protofibrils [6].

Important insight into $A \beta$ aggregation came from structures of $A \beta_{40}[7,8]$ and $A \beta_{42}$ [9] in the fibril state, that were determined by NMR techniques. For the monomeric subunits, both structures consistently reveal two $\beta$-strands connected by a turn, thus forming a U-shaped topology [8-10]. The monomeric subunits form a longitudinal stack, thereby creating two parallel in-register $\beta$-sheets (Fig. 1a). Key features of $A \beta$-fibril stability are the intermolecular salt bridges between D23 of the $i^{\text {th }}$ and $\mathrm{K} 28$ of the $(i+1)^{\text {th }} \mathrm{A} \beta$ monomer and the inter-sheet side chain packing interactions between hydrophobic residues of the $i^{\text {th }}$ and its two adjacent layers (i-1, $\mathrm{i}+1)$, thus forming a cross $\beta$-structure. Amyloid growing can proceed longitudinally, i.e. the adsorption of new monomers along the fibril axis (Fig. 1a), and laterally, i.e. the association of another stack of monomers at the lateral surface of the growing aggregate [815]. Lateral association might either occur via the $\mathrm{N}$-terminal or via the $\mathrm{C}$-terminal $\beta$-sheet, resulting in the so-called NN-interface (Fig. 1d) or the CC-interface (Fig. 1c).

While originally the extracellular fibrillar plaque deposition was assumed to be the disease initiating event $[16,17]$, today increasing evidence suggests that small soluble oligomers are the direct effectors of synaptic and cognitive dysfunction in AD [18, 19]. Moreover, it is even speculated that fibrillar plaques are rather neuroprotective [20]. The novel theory is supported by the pathological E22-A $\beta$-amyloid point mutants that are characterized by both an accelerated formation of $A \beta$-intermediate states and an enhanced amyloid neurotoxicity but less fibril formation [21, 22]. Aggregation properties, neurotoxicity and pathology of the Arctic (E22G), Italian (E22K), and Dutch (E22Q) variants are summarized in Table 1. The 
E22 $\Delta$ variant, which was recently discovered in Japan, exhibits an enhanced aggregation rate compared to the wild type and is characterized by a strong enrichment of small soluble oligomers, which are highly resistant to proteolytic digestion [23]. Finally, E22 deletion was found to inhibit long term potentiation more efficiently, and to induce synaptic alterations more potently than wild type A $\beta$-amyloid [24]. These findings demonstrate that not only the mutation of residue E22 leads to pathogenic effects but also the deletion of this residue.

While the E22 $\Delta$ variant is yet completely uncharacterized from a structural point of view, there exist several computational studies, which aimed to characterize the molecular effects underlying increased aggregate formation by $A \beta$ point mutants. Most studies focused either on the initial nucleation step leading to oligomers $[12,25]$, or on the lateral association step which is relevant for the formation of the fibril quaternary structure [13]. The effect of the mutations E22G, E22Q, and E22K on A $\beta$-nucleation has been investigated by Krone et al. [25] using the $A \beta$ (21-30) segment as model system. From their work the authors conclude that substitutions at E22 do little to alter the overall structure of the monomeric fragment and that E22 might rather affect long-range interactions outside the monomeric structure [25]. The effect of E22 mutation on the formation of the $A \beta_{42}$-association has been studied by Zheng et al. [13]. Mutation was found to hamper the formation of the NN-interface (Fig. 1d), in which an E22-K16 bridge is formed between adjacent stacks of the protofibril. These findings suggest that the enrichment of oligomers is mainly a result of the inability of mutant oligomers to become incorporated into fibrils. The experimental data, however, shows that mutant oligomers are not only enriched but also exhibit an increased stability, e.g. resistance to proteolytic degradation and a higher aggregation rate $[23,24]$. This observation indicates that there exist additional structural properties, which lead to an increased internal stability of mutant $A \beta$-oligomers.

To address this point, the present work investigated the structure, dynamics and energetics of wild type and mutant $A \beta$-pentamers, including the structurally yet completely uncharacterized deletion mutant E22 $\Delta$. For this purpose, molecular dynamics simulations have been performed for the different systems. The significant differences of the internal stability of wild type and mutant pentamers detected are likely to play a key role for the pathogenicity of these mutants. 


\section{Materials and methods}

\section{Preparation of starting structures}

All models and simulations are based on the $A \beta_{17-42}$ pentamer structure that was obtained from NMR-spectroscopic data (PDB entry 2BEG; model 10) [9]. Residues 15-16 were added to the model in an extended conformation to ensure the $\beta$-sheet complementarity of the Ushaped pentamer and to account for the secondary structure in the fibrillar form [26, 27]. Point mutants were generated starting from the elongated version of the wild type pentamer by using SYBYL7.3 [28]. The side chain of E22 was replaced in each monomer of the pentamer by that of glycine, lysine or glutamine to obtain the Arctic (E22G), Italian (E22K), and Dutch (E22Q) mutants. The structure of the E22 $\Delta-\mathrm{A} \beta$-amyloid deletion mutant was obtained by homology modeling with MODELLER6.2 [29] using the wiltype pentamer as template. All structures were N-terminally acetylated using SYBYL7.3 followed by 100 steps of conjugate gradient minimization to release bad contacts.

\section{Molecular dynamics simulations}

All MD simulations were performed by using the AMBER9 [30] suite of programs with the force field ff99SB [31] that augments the united parameter sets of ff94 [32] and ff99 [33, 34] with updated torsion potentials. The systems were neutralized by the addition of an appropriate number of sodium or chloride counter ions. Subsequently the molecules were solvated in a water box using the TIP3P water model [35].

Minimization and molecular dynamics were carried out using the SANDER module of AMBER9 with default settings for non-bonded interactions. Particle Mesh Ewald summation [36] was used to calculate the long-range electrostatic interactions. Minimization was carried out in two subsequent steps. In a first step only water molecules were minimized while restraining all protein atoms on their initial positions with a force constant of 5,000 kcal mol${ }^{-1}$ $\mathrm{A}^{-2}$. In the second step, additional relaxation of counter ions and protons was allowed by restraining all heavy atoms of the protein with a force constant of $50 \mathrm{kcal} \mathrm{mol}^{-1} \mathrm{~A}^{-2}$. In both minimizations, 250 steps of steepest descent were followed by 250 steps of conjugate gradient minimization.

MD simulations were carried out thereafter using a time step of $1 \mathrm{fs}$ and periodic boundary conditions. The SHAKE procedure [37] was applied to fix all bonds involving hydrogen 
atoms. The temperature of the system was gradually raised from $10 \mathrm{~K}$ to $300 \mathrm{~K}$ in two subsequent equilibration steps of 0.5 and $2.5 \mathrm{~ns}$. In both equilibration steps restraints were set. In step one all protein backbone and side chain heavy atoms were fixed while in step two still all backbone heavy atoms were kept on their initial positions. In the following, an unconstrained $20 \mathrm{~ns}$ production phase with standard NPT conditions at 1 bar was performed for data collection, saving coordinates every 1 ps to produce a total of 20,500 snapshots (including equilibration). Hierarchical clustering [38] of the 20,000 snapshots obtained during the production phase was performed using the ptraj program of AMBER10 [39]. Results were analyzed and visualized using the programs AMBER, SYBYL7.3 [28], VMD [40], and DS ViewerPro 6 [41].

\section{Energetic analysis}

Since the pentameric system contains multiple protein-protein interfaces, energetic analysis requires the definition of a suitable interface. Because the present study aimed to assess the internal stability of the $\mathrm{A} \beta$-pentamer, we measured the interaction energy between the middle chain $\mathrm{C}$ and the remaining four chains (A-B, D-E) of the pentamer (Fig. 2). The respective interaction energy represents the strength by which the middle chain clamps the $A \beta$-stack together and was therefore termed $\Delta \mathrm{G}_{\text {clamp. }}$ The interaction free energy $\Delta \mathrm{G}_{\text {clamp }}$ for the central A $\beta$-layer was calculated according to the standard MM/GBSA approach [42]:

$$
\Delta G_{\text {clamp }}=\Delta G_{M M}+\Delta G_{\text {sol }}-T \Delta S
$$

$\Delta G_{M M}$ is the molecular mechanics energy for the interaction between the ligand and the receptor, and $\Delta G_{s o l}$ is the solvation free energy. $-T \Delta S$ is the entropic contribution, which was estimated from normal mode analysis using the NMODE program of AMBER. $\Delta G_{M M}$ is calculated according to Eq. 2,

$$
\Delta G_{M M}=\Delta G_{\mathrm{int}}^{e l e}+\Delta G_{\mathrm{int}}^{v d w}
$$

whereas the electrostatic and van-der-Waals interaction energies, $\Delta G_{\text {int }}^{\text {ele }}$ and $\Delta G_{\text {int }}^{\text {vdw }}$, were calculated with the AMBER module SANDER. Likewise, the solvation free energy $\Delta \mathrm{G}_{\mathrm{sol}}$, is composed of an electrostatic ( $\left.\Delta G_{\text {sol }}^{\text {ele }}\right)$ and a nonpolar $\left(\Delta G_{\text {sol }}^{\text {nonolar }}\right)$ energy term (Eq. 3) 


$$
\Delta G_{\text {sol }}=\Delta G_{\text {sol }}^{\text {ele }}+\Delta G_{\text {sol }}^{\text {nonpolar }}
$$

The electrostatic contribution ( $\Delta G_{\text {sol }}^{\text {ele }}$ ) was calculated using the generalized born (GB) method implemented in SANDER, while nonpolar contributions to the solvation free energy $\left(\Delta G_{\text {sol }}^{\text {nonpolar }}\right.$ ) were calculated as a function of the solvent accessible surface area (SA) [43] using AMBER9 default parameters for $\gamma$ and $b$ [30] (Eq. 4).

$$
\Delta G_{\text {sol }}^{\text {nonolar }}=\gamma \times S A+b
$$

The contributions of individual side chains to the pentamer stability were estimated form an in silico alanine scan, in which the amino acids of chain $\mathrm{C}$ were individually replaced by alanine. For the calculation of $\Delta \Delta G$, we followed the standard protocol described by Massova and Kollman [44], which assumes that the entropy of the alanine mutant and the wild type do not differ significantly, and therefore entropic contributions can be omitted for the calculation of $\Delta \Delta G$ in this type of analysis. Alanine scanning and MM/GBSA analysis for wild type $\mathrm{A} \beta-$ amyloid and all mutants was performed on a total of 91 pdb structures taken from the trajectory during $2.5-20.5 \mathrm{~ns}$ simulation time by selecting every $200^{\text {th }}$ snapshot.

\section{Results and discussion}

\section{Mutant $\mathrm{A} \boldsymbol{\beta}_{42}$ oligomers are more rigid than the wild type}

The wild type $A \beta$ exhibits root mean square deviations (RMSD) from the starting structure of

6-8 $\AA$ (Fig. 3). The magnitude of these fluctuations is consistent with the findings of a previous $A \beta$ simulation, which obtained very similar RMSD values for the A $\beta$-pentamer [13]. Interestingly, all mutants investigated in the present study exhibit smaller RMSD values than the wild type. The highest conformational stability is observed for the mutants E22G, E22K, and E22 $\Delta$, which show RMSD values of less than $4 \AA$ for most parts of the simulation.

This finding also indicates that the high RMSD detected for the wild type can rather be attributed to particular sequence properties of the wild type than to inaccuracies of the starting model. In case of an inaccurate starting structure, large RMSD values would be expected for 
all simulations. In contrast, the present study reveals that the conformational stability of $A \beta$ oligomers is highly dependent on the identity of the amino acid at sequence position 22 .

Visual inspection of the trajectories together with RMSD profiles and the structures produced over the trajectory (Fig. 4) proved that the overall $\mathrm{A} \beta$ structure was stable in all simulations. The U-shaped arrangement of the two stacked parallel $\beta$-sheets and the intermolecular D23/K28 salt bridges are preserved in all simulations. The higher RMSD values detected for the wild type and the E22Q mutant mainly originate from a larger twist of the $\beta$-sheets (Fig. 4). The presence of a twist is consistent with experimental data obtained from electron micrographs of $A \beta$ fibrils [9] and might represent a prerequisite for the incorporation of oligomers into fibrils.

\section{Special structural properties of the E22 $\Delta$ mutant}

The observation that the overall fibril geometry is retained even after the deletion of E22 and that this mutant is even more stable than the wild type might be surprising at first glance. Therefore, the effect of E22 deletion on the backbone geometry was analyzed in more detail. Significant differences of the backbone torsion angles between wild type and E22 $\Delta$ were only observed for the three residues C-terminally adjacent to the site of deletion (Fig. 5). D23 adopts a turn structure in the mutant instead of an extended conformation in the wild type. A very similar change from an extended conformation in the wild type to a turn structure is also observed for G25, while the V24 backbone undergoes only smaller changes.

Taken together, these changes lead to an alternative backbone conformation of residues D23V25 in E22 2 , while the backbone conformation of the remaining residues is not significantly affected by the mutation. The backbone topology of E22 $\Delta$ is stable over the entire simulation time and shows only minor fluctuations (Fig. 5). Importantly, this conformation also allows the preservation of the inter-chain D23-K28 salt bridge in the mutant (Fig. 4e, 6), which was described previously to play a crucial role for pentamer stability [9].

The observation that the sequence region, which connects both $\beta$-strands, exhibits a certain degree of variability is also consistent with previous studies. The models derived thus far for $\mathrm{A} \beta_{40}[7,8,10,45]$ and $\mathrm{A} \beta_{42}$ [9] filaments consistently show two $\beta$-strands and a buried D23K28 salt bridge that stabilizes the connecting turn. The exact length and geometry of the turn, however, varies between these models. These findings suggest that $\mathrm{A} \beta$ exhibits a particular 
conformational plasticity in this region, which does not only allow the formation of distinct turn geometries, but even tolerates the deletion of one residue.

\section{Energetic analysis indicates a destabilizing effect of E22}

The RMSD values obtained over the MD simulations (Fig. 3) reveal a higher conformational stability of mutant $A \beta_{42}$ oligomers compared to the wild type. As the five pentamers differ solely by the amino acid on position 22 , this residue appears to be the crucial determinant for stability in the investigated systems.

The alanine scan reveals a similar profile for the wild type and mutants (Fig. 7a). This indicates that the role of the individual side chains for the overall stabilization is comparable in all pentamers investigated. This is consistent with the fact that the overall A $\beta$-fold is preserved in all simulations (Fig. 4). The alanine scan also reveals those side chains, which play a particular important role: The residues D23 and K28, which form inter-chain salt bridges, as well as the hydrophobic residues L17, F19 and F20 are the main contributors to $A \beta_{42}$ oligomer internal stability (Fig. 7a). Analysis of wild type $A \beta_{42}$ (Fig.7a; black bars) further reveals that all side chains except E22 exert a stabilizing effect on the pentamer fold. This is reflected by the positive $\Delta \Delta G$ values indicating that a replacement of the respective side chain would weaken the interactions with adjacent chains in the wild type pentamer. E22, which represents the site of mutation, evidently plays a unique role, since the glutamate present in the wild type leads to a destabilization of approximately $3 \mathrm{kcal} \mathrm{mol}^{-1}$ compared to a uncharged alanine. The structural explanation for this destabilizing effect comes from the arrangement of the $A \beta$-stack as parallel $\beta$-sheet, which places the negatively charged E22-side chains of adjacent layers in immediate vicinity to each other (Fig. 1a).

Mutations, which change E22 to a uncharged residue, are therefore expected to abrogate repulsion between adjacent $A \beta$-chains and to result in a stabilization of the pentamer. Such a situation is present for the E22G and E22Q mutants. While no alanine scan can be performed for position 22 in E22G due to the simulation setup, the stabilizing effect of G22 and Q22 can clearly be seen from the plot of the electrostatic interaction energy shown in Fig. 7b. It is also interesting to note that electrostatic repulsion is less severe for E22K compared to the wild type (Fig. 7a,b). This finding can most likely be explained by the fact that the longer K22 side chain has a larger conformational freedom and can therefore adopt alternative conformations, which more efficiently reduce the repulsion of adjacent $A \beta$-layers. 
In order to quantify the effect of E22 mutation, the stability of the stack was estimated from calculating the free energies of stabilization $\left(\Delta \mathrm{G}_{\text {clamp }}\right)$ for the middle $A \beta$-chain from a MM/GBSA analysis (see Methods for details). The respective interaction energy represents the strength by which the middle chain clamps the $A \beta$-stack together and was therefore used as a measure for the internal stability of the pentamer.

The negative $\Delta \Delta \mathrm{G}_{\text {clamp }}$ values of -8.0 to $-26.1 \mathrm{kcal} \mathrm{mol}^{-1}$ indicate that all mutant $A \beta$-pentamers exhibit a higher internal stability than the wild type (Table 2). In addition, the analyses demonstrate that not only the mutation of E22, but also the complete deletion of this residue results in enhanced pentamer stability. Oligomers with a deleted residue E22 or an E22G/Q point mutation show a higher internal stability compared to the E22K mutation (Table 2) indicating a higher oligomerization tendency. This is in accordance with previous experimental studies, which give numerous evidence for E22G and E22Q to form nonfibrillar toxic assemblies, while for E22K generally a lower toxicity and aggregation potency are reported [22, 46-49]. In addition, our observations match the stated correlation between hydrophobicity and charge at position 22 and aggregation rate of $\mathrm{A} \beta$-amyloid that describes an increased aggregation rate with gaining hydrophobicity [50]. Thus, the observed lower aggregation tendency of E22K meets this correlation.

\section{Effects of E22 mutation on fibril formation}

The data above offers a structural explanation for the experimental observation that the lack of glutamate at position 22 facilitates the formation of stable oligomers. In addition to enhanced oligomer stability, the mutants also exhibit a hampered formation of fibrils as a second common property (Table 1). The impeded fibrillation of mutant A $\beta$ was computationally investigated in a previous study [13] and has mainly been attributed to the lack of stabilizing interactions within the lateral interface, like the loss of an intermolecular E22-K16 salt bridge (Fig. 1d). A second effect on fibril formation, which emerges from our study, might result from the altered dynamics of the mutant pentamers: It is known from electron microscopic data [51] that fibrils are significantly twisted along their axis. Such twisting requires a certain degree of internal flexibility of the two $\beta$-sheets against each other. Our simulations revealed that the wild type has a high internal flexibility (Fig. 3) and that twisting is less pronounced in the mutants (Fig. 4). This effect should generally hamper the lateral association of mutant $\mathrm{A} \beta$, regardless of the interface involved. In this context, the finding that the E22 $\Delta$ variant exhibits a particular rigid structure (Fig. 3), also offers an 
explanation for the experimental observation, that this mutant shows a complete lack of fibrillation [23].

\section{Conclusions}

The findings above suggest that there exist at least two structural effects of the mutations at position 22 (Fig. 8). Firstly, the mutant oligomers themselves exhibit a higher internal stability due to the lack of electrostatic repulsion between adjacent E22 residues. Secondly, the mutant oligomers can no longer be incorporated into fibrils. Together, both effects suggest a mechanism for the enrichment and enhanced stability of $A \beta$-oligomers observed in experimental studies (Table 1).

This dual effect of E22 mutations offers an explanation, why changes at this sequence position have such a drastic effect on the progression of the disease. Finally, these findings affirm the oligomer hypothesis of $\mathrm{AD}$ that claims prefibrillar aggregates and oligomers to be direct effectors of synaptic and cognitive dysfunction in AD (Fig. 8). The correlation between internal stability, aggregation tendency, and pathogenicity might also be helpful for the design of drugs targeting small but toxic $\mathrm{A} \beta$-amyloid compounds.

\section{Acknowledgments}

The authors thank the High Performance Computing group of the Regionales Rechenzentrum Erlangen for providing AMBER executables optimized for parallel execution. This work was funded by the Volkswagen Foundation. 


\section{References}

1. Alzheimer A (1907) Über eine eigenartige Erkrankung der Hirnrinde. Allg Z Psychiat Psych-Gerichtl Med 64:146-148

2. Siegel G, Albers RW, Brady S, Price D (2005) Basic Neurochemistry, $7^{\text {th }}$ edn. Elesevier Academic Press

3. Brun A, Englund E (1981) Regional pattern of degeneration in Alzheimer's disease: neuronal loss and histopathological grading. Histopathology 5:549-564

4. Morris JC, Price AL (2001) Pathologic correlates of nondemented aging, mild cognitive impairment, and early-stage Alzheimer's disease. J Mol Neurosci 17:101-118

5. Irie K, Murakami K, Masuda Y, Morimoto A, Ohigashi H, Ohashi R, Takegoshi K, Nagao M, Shimizu T, Shirasawa T (2005) Structure of beta-amyloid fibrils and its relevance to their neurotoxicity: implications for the pathogenesis of Alzheimer's disease. J Biosci Bioeng 99:437-447

6. Finder VH, Glockshuber R (2007) Amyloid-beta aggregation. Neurodegener Dis 4:13-27

7. Petkova AT, Ishii Y, Balbach JJ, Antzutkin ON, Leapman RD, Delaglio F, Tycko R (2002) A structural model for Alzheimer's beta -amyloid fibrils based on experimental constraints from solid state NMR. Proc Natl Acad Sci USA 99:16742-16747

8. Petkova AT, Yau WM, Tycko R (2006) Experimental constraints on quaternary structure in Alzheimer's beta-amyloid fibrils. Biochemistry 45:498-512

9. Lührs T, Ritter C, Adrian M, Riek-Loher D, Bohrmann B, Dobeli H, Schubert D, Riek R (2005) 3D structure of Alzheimer's amyloid-beta(1-42) fibrils. Proc Natl Acad Sci USA 102:17342-17347

10. Ma B, Nussinov R (2006) Simulations as analytical tools to understand protein aggregation and predict amyloid conformation. Curr Opin Chem Biol 10:445-452

11. Sato T, Kienlen-Campard P, Ahmed M, Liu W, Li H, Elliott JI, Aimoto S, Constantinescu SN, Octave JN, Smith SO (2006) Inhibitors of amyloid toxicity based on beta-sheet packing of Abeta40 and Abeta42. Biochemistry 45:5503-5516

12. Fawzi NL, Kohlstedt KL, Okabe Y, Head-Gordon T (2008) Protofibril assemblies of the arctic, Dutch, and Flemish mutants of the Alzheimer's Abeta1-40 peptide. Biophys J 94:2007-2016

13. Zheng J, Jang H, Ma B, Tsai CJ, Nussinov R (2007) Modeling the Alzheimer Abeta17-42 fibril architecture: tight intermolecular sheet-sheet association and intramolecular hydrated cavities. Biophys J 93:3046-3057 
14. Zheng J, Ma B, Chang Y, Nussinov R (2008) Molecular dynamics simulations of Alzheimer Abeta40 elongation and lateral association. Front Biosci 13:3919-3930

15. Zheng J, Jang H, Ma B, Nussinov R (2008) Annular structures as intermediates in fibril formation of Alzheimer Abeta17-42. J Phys Chem B 112:6856-6865

16. Selkoe DJ (1991) The molecular pathology of Alzheimer's disease. Neuron 6:487-498

17. Hardy J, Selkoe DJ (2002) The amyloid hypothesis of Alzheimer's disease: progress and problems on the road to therapeutics. Science 297:353-356

18. McLean CA, Cherny RA, Fraser FW, Fuller SJ, Smith MJ, Beyreuther K, Bush AI, Masters CL (1999) Soluble pool of Abeta amyloid as a determinant of severity of neurodegeneration in Alzheimer's disease. Ann Neurol 46:860-866

19. Haass C, Selkoe DJ (2007) Soluble protein oligomers in neurodegeneration: lessons from the Alzheimer's amyloid beta-peptide. Nat Rev Mol Cell Biol 8:101-112

20. Caughey B, Lansbury PT (2003) Protofibrils, pores, fibrils, and neurodegeneration: separating the responsible protein aggregates from the innocent bystanders. Annu Rev Neurosci 267-298

21. Murakami K, Irie K, Morimoto A, Ohigashi H, Shindo M, Nagao M, Shimizu T, Shirasawa T (2003) Neurotoxicity and physicochemical properties of Abeta mutant peptides from cerebral amyloid angiopathy: implication for the pathogenesis of cerebral amyloid angiopathy and Alzheimer's disease. J Biol Chem 278:46179-46187

22. Nilsberth C, Westlind-Danielsson A, Eckman CB, Condron MM, Axelman K, Forsell C, Stenh C, Luthman J, Teplow DB, Younkin SG, Naslund J, Lannfelt L (2001) The 'Arctic' APP mutation (E693G) causes Alzheimer's disease by enhanced Abeta protofibril formation. Nat Neurosci 4:887-893

23. Tomiyama T, Nagata T, Shimada H, Teraoka R, Fukushima A, Kanemitsu H, Takuma H, Kuwano R, Imagawa M, Ataka S, Wada Y, Yoshioka E, Nishizaki T, Watanabe Y, Mori $\mathrm{H}$ (2008) A new amyloid beta variant favoring oligomerization in Alzheimer's-type dementia. Ann Neurol 63:377-387

24. Takuma H, Teraoka R, Mori H, Tomiyama T (2008) Amyloid-beta E22Delta variant induces synaptic alteration in mouse hippocampal slices. Neuroreport 19:615-619

25. Krone MG, Baumketner A, Bernstein SL, Wyttenbach T, Lazo ND, Teplow DB, Bowers MT, Shea JE (2008) Effects of familial Alzheimer's disease mutations on the folding nucleation of the amyloid beta-protein. J Mol Biol 381:221-228 
26. Olofsson A, Sauer-Eriksson AE, Ohman A (2006) The solvent protection of alzheimer amyloid-beta-(1-42) fibrils as determined by solution NMR spectroscopy. J Biol Chem 281:477-483

27. Olofsson A, Sauer-Eriksson AE, Ohman A (2009) Amyloid fibril dynamics revealed by combined hydrogen/deuterium exchange and nuclear magnetic resonance. Anal Biochem $385: 374-376$

28. Tripos (1991-2008) Sybyl7.3. St. Louis, Missouri, USA

29. Eswar N, Eramian D, Webb B, Shen MY, Sali A (2008) Protein structure modeling with MODELLER. Methods Mol Biol 145-159

30. Case DA, Darden TA, Cheatham TE, Simmerling CL, Wang J, Duke RE, Luo R, Merz KM, Pearlman DA, Crowley M, Walker RC, Zhang W, Wang B, Hayik S, Roitberg A, Seabra G, Wong KF, Paesani F, Wu X, Brozell S, Tsui V, Gohlke H, Yang L, Tan C, Mongan J, Hornak V, Cui G, Beroza P, Mathews DH, Schafmeister C, Ross WS, Kollman PA (2006) AMBER9. University of California, San Francisco, USA

31. Hornak V, Abel R, Okur A, Strockbine B, Roitberg A, Simmerling C (2006) Comparison of multiple Amber force fields and development of improved protein backbone parameters. Proteins 65:712-725

32. Cornell WD, Cieplak P, Bayly CI, Gould R, Merz KMJ, Ferguson DM, Spellmeyer DC, Fox T, Caldwell JW, Kollman PA (1995) A Second Generation Force Field for the Simulation of Proteins, Nucleic Acids and Organic Molecules. J Am Chem Soc 117:5179-5197

33. Cheatham TE, 3rd, Cieplak P, Kollman PA (1999) A modified version of the Cornell et al. force field with improved sugar pucker phases and helical repeat. J Biomol Struct Dyn $16: 845-862$

34. Wang J, Cieplak P, Kollman PA (2000) How well does a restrained electrostatic potential (RESP) model perform in calculating conformational energies of organic and biological molecules? J Comput Chem 21:1049-1074

35. Jorgensen WL, Chandrasekhar J, Madura JD, Impey RW, Klein ML (1983) Comparison of simple potential functions for simulationg liquid water. J Chem Phys 79:926-935

36. Darden TA, York DM, Pedersen LG (1993) Particle Mesh Ewald. An N.log(N) method for Ewald sums in large systems. J Chem Phys 98:10089-10092

37. Ryckaert JP, Ciccotti G, Berendsen HJC (1977) J Comput Phys 23:327-341 
38. Shao J, Tanner SW, Thompson N, Cheatham TE, III (2007) Clustering molecular dynamics trajectories: 1. Characterizing the performance of different clustering altorithms. J. Chem. Theory Comput. 3:2312-2334

39. Pearlman DA, Darden TA, Cheatham TE, III, Simmerling CL, Wang J, Duke RE, Luo R, Crowley M, Walker RC, Zhang W, Merz KM, Wang B, Hayik S, Roitberg A, Seabra B, Kolossováry I, Wong KF, Paesani F, Vanicek J, Wu X, Brozell S, Steinbrecher T, Gohlke H, Yang L, Tan C, Mongan J, Hornak V, Cui G, Mathews DH, Seetin MG, Sagui C, Babin V, Kollman PA (2008) Amber 10, San Francisco

40. Humphrey W, Dalke A, Schulten K (1996) VMD: visual molecular dynamics. J Mol Graph 14:33-38, 27-38

41. Accelrys (2005) DS ViewerPro Suite 6.0. San Diego, CA, USA

42. Kollman PA, Massova I, Reyes C, Kuhn B, Huo S, Chong L, Lee M, Lee T, Duan Y, Wang W, Donini O, Cieplak P, Srinivasan J, Case DA, Cheatham TE $3^{\text {rd }}(2000)$ Calculating structures and free energies of complex molecules: combining molecular mechanics and continuum models. Acc Chem Res 33:889-897

43. Sitkoff D, Sharp K, Honig B (1994) Accurate calculation of hydration free energies using macroscopic sovent models. J Phys Chem 98:1978-1988

44. Massova I, Kollmann PA (1999) Computational Alanine Scanning To Probe ProteinProtein Interactions: A Novel Approach To Evaluate Binding Free Energies. J Am Chem Soc 121:8133-8143

45. Petkova AT, Leapman RD, Guo Z, Yau WM, Mattson MP, Tycko R (2005) Selfpropagating, molecular-level polymorphism in Alzheimer's beta-amyloid fibrils. Science 307:262-265

46. Whalen BM, Selkoe DJ, Hartley DM (2005) Small non-fibrillar assemblies of amyloid beta-protein bearing the Arctic mutation induce rapid neuritic degeneration. Neurobiol Dis 20:254-266

47. Miravalle L, Tokuda T, Chiarle R, Giaccone G, Bugiani O, Tagliavini F, Frangione B, Ghiso J (2000) Substitutions at codon 22 of Alzheimer's abeta peptide induce diverse conformational changes and apoptotic effects in human cerebral endothelial cells. J Biol Chem 275:27110-27116

48. Sian AK, Frears ER, El-Agnaf OM, Patel BP, Manca MF, Siligardi G, Hussain R, Austen BM (2000) Oligomerization of beta-amyloid of the Alzheimer's and the Dutch-cerebralhaemorrhage types. Biochem J 349:299-308 
49. Paris D, Ait-Ghezala G, Mathura VS, Patel N, Quadros A, Laporte V, Mullan M (2005) Anti-angiogenic activity of the mutant Dutch $\mathrm{A}$ (beta) peptide on human brain microvascular endothelial cells. Brain Res Mol Brain Res 136:212-230

50. Päiviö A, Jarvet J, Graslund A, Lannfelt L, Westlind-Danielsson A (2004) Unique physicochemical profile of beta-amyloid peptide variant Abeta1-40E22G protofibrils: conceivable neuropathogen in arctic mutant carriers. J Mol Biol 339:145-159

51. Tycko R (2006) Molecular structure of amyloid fibrils: insights from solid-state NMR. Q Rev Biophys 39:1-55

52. Eisenhauer PB, Johnson RJ, Wells JM, Davies TA, Fine RE (2000) Toxicity of various amyloid beta peptide species in cultured human blood-brain barrier endothelial cells: increased toxicity of dutch-type mutant. J Neurosci Res 60:804-810 
Table 1 Aggregation properties (rate of aggregation, neurotoxicity and pathology) of disease associated E22-A $\beta$ mutants compared to the wild type

\begin{tabular}{lllll}
\hline & Rate & \multicolumn{1}{c}{ Morphology } & Neurotoxicity & Pathology \\
\hline E22G (Arctic)[22, 46] & accelerated & Small protofibrils and oligomers & enhanced & AD dementia \\
E22K (Italian)[21] & accelerated & Less fibrillar & enhanced & CAA $^{\text {a }}$ \\
E22Q (Dutch) $[21,52]$ & accelerated & Rather amorphous than fibrillar; oligomers & enhanced & CAA \\
E22 (Japanese)[23] & accelerated & Small soluble oligomers, lack of fibrils & enhanced & AD dementia \\
\hline${ }^{{ }^{a} C A A, \text { cerebral amyloid angiopathy }}$ & & & &
\end{tabular}


Table 2 Interaction energies (in $\mathrm{kcal} \mathrm{mol}^{-1}$ ) of the middle chain $\mathrm{C}$ with the remaining four chains of the A $\beta$-pentamer. Values were calculated for the wild type, E22G, E22K, E22Q, and E22 $\Delta$ using the MM/GBSA strategy (see Methods for details). Differences of the interaction energies $\left(\Delta \Delta \mathrm{G}_{\text {clamp }}\right)$ were obtained using the wild type $\Delta \mathrm{G}_{\text {clamp }}$-value as reference

\begin{tabular}{lrrrrrrrr}
\hline & $\boldsymbol{\Delta} \mathbf{G}_{\text {int }}{ }^{\text {ele }}$ & $\boldsymbol{\Delta G}_{\text {int }}{ }^{\text {vdw }}$ & $\boldsymbol{\Delta} \mathbf{G}_{\text {sol }}^{\text {ele }}$ & $\boldsymbol{\Delta G}_{\text {sol }}^{\text {nonpolar }}$ & $\boldsymbol{\Delta} \mathbf{G}_{\text {sol }}$ & $\mathbf{T} \boldsymbol{\Delta} \mathbf{S}$ & $\boldsymbol{\Delta} \mathbf{G}_{\text {clamp }}$ & $\boldsymbol{\Delta} \boldsymbol{\Delta} \mathbf{G}_{\text {clamp }}$ \\
\hline $\mathrm{Wt}$ & $-4.4 \pm 0.3$ & $-239.1 \pm 0.2$ & $+64.3 \pm 0.3$ & $-33.7 \pm 0.0$ & $+30.5 \pm 0.3$ & -80.6 & -132.4 & - \\
$\mathrm{E} 22 \mathrm{G}$ & $-191.7 \pm 0.4$ & $-246.9 \pm 0.1$ & $+232.3 \pm 0.3$ & $-35.4 \pm 0.0$ & $+196.9 \pm 0.3$ & -83.8 & -158.0 & -25.6 \\
$\mathrm{E} 2 \mathrm{~K}$ & $+37.1 \pm 0.3$ & $-245.3 \pm 0.1$ & $+12.3 \pm 0.3$ & $-34.6 \pm 0.0$ & $-22.4 \pm 0.3$ & -90.2 & -140.4 & -8.0 \\
$\mathrm{E} 22 \mathrm{Q}$ & $-193.8 \pm 0.4$ & $-250.8 \pm 0.1$ & $+237.1 \pm 0.3$ & $-34.2 \pm 0.0$ & $+202.9 \pm 0.3$ & -83.2 & -158.5 & -26.1 \\
$\mathrm{E} 22 \Delta$ & $-208.0 \pm 0.4$ & $-241.9 \pm 0.1$ & $+243.7 \pm 0.3$ & $-34.4 \pm 0.0$ & $+209.3 \pm 0.3$ & -83.3 & -157.3 & -24.9 \\
\hline
\end{tabular}




\section{Figure captions}

Fig. 1 (a) Schematic representation of the $A \beta_{42}$-Amyloid pentamer structure used in the present study. The pentamer is composed of chains A-E. Highlighted are the two parallel in-register $\beta$-sheets, sheet $\beta 1$ (red) and sheet $\beta 2$ (black). The pentamer is stabilized by intermolecular D23-K28 salt bridges, exemplified by the first salt bridge between D23 of chain A and K28 of chain B, and hydrophobic inter-sheet packing interactions, exemplified for the packing of residues A21 and F19 of chain A with V36 and G38 of chain B. An arrow indicates the direction of longitudinal growth. Negatively charged, positively charged, polar, and hydrophobic residues are colored in red, blue, green, and grey, respectively. The key residue E22 is indicated with a red box. (b) ( $\beta 1$-strand)-loop-( $\beta 2$-strand) motif of a monomeric subunit showing the side chain orientation of residues 15-42 in detail. (c) and (d) Structural model of double-layered $A \beta_{42}$-pentamers illustrating the principles of fibril formation via lateral association. Lateral association might either proceed via the $\mathrm{N}$-terminal strand $\beta 1(\mathbf{d})$ or the $\mathrm{C}$-terminal strand $\beta 2$ (c) thus resulting in the socalled NN- or CC-interface

Fig. 2 Schematic drawing of the setup used for estimating the internal stability of the wild type and mutant pentamers. Free energies of interaction were calculated between the middle chain $\mathrm{C}$ (grey) and the remaining four chains (A-B, D-E) of the pentamer, thus reflecting the strength by which chain $\mathrm{C}$ clamps the $\mathrm{A} \beta$ stack together

Fig. 3 Conformational stability of wild type and mutant A $\beta$-pentamers. Wild type, E22G, $\mathrm{E} 22 \mathrm{~K}, \mathrm{E} 22 \mathrm{Q}$, and E22s are colored in black, grey, blue, green and red, respectively. The RMSD was measured to the corresponding initial structure in each system

Fig. 4 Side and top view of representative structures of wild type and mutant $A \beta$ pentamers. (a) wild type, (b) E22G, (c) E22K, (d) E22Q, and (e) E22 . Sheets $\beta 1$ and $\beta 2$ are colored in red and black, respectively. The loop is colored in grey. The salt bridge forming residues D23 and K28 are indicated. Arrows point towards growth direction with chain $\mathrm{A}$ on the growing end 
Fig. 5 Dihedral angles of residues E22 to G25 of chain C as a function of simulation time. $\varphi$ angle $\left(\mathrm{C}_{\mathrm{i}-1}-\mathrm{N}_{\mathrm{i}}-\mathrm{C}^{\alpha}{ }_{\mathrm{i}}-\mathrm{C}_{\mathrm{i}}\right)$ in black, $\psi$ angle $\left(\mathrm{N}_{\mathrm{i}}-\mathrm{C}^{\alpha}{ }_{\mathrm{i}}-\mathrm{C}_{\mathrm{i}}-\mathrm{N}_{\mathrm{i}+1}\right)$ in grey. Angles for the wild type and E22 $\Delta$ variant are shown on the left and right side, respectively. $\Delta$ indicates deleted residue E22

Fig. 6 Salt bridges formed by D23 and K28 of chain C in the wiltype (black) and mutant (grey). (a) Interaction between K28 of chain C and D23 of chain B. (b) Interaction between D23 of chain C and K28 of chain D

Fig. 7 Energetic analysis of $A \beta$-mutants (a) Alanine scanning of wild type and $E 22-A \beta_{42}$ mutants. Shown are the contributions of individual side chains to the interaction free energy $\left(\Delta \Delta \mathrm{G}_{\text {clamp }}\right)$ of chain $\mathrm{C}$ to the adjacent four chains of the pentamer. Positive values indicate a stabilizing effect of the respective amino acid compared to alanine. No scan was performed for alanine and glycine. (b) Electrostatic interaction energy $\left(E_{\text {ele }}\right)$ of residue 22 of chain $C$ to the adjacent four chains $(A-B$, D-E) as function of simulation time. The wild type, E22G, E22K, and E22Q mutants are colored in black, grey, blue, and green, respectively

Fig. 8 Schematic representation showing the effects of E22 deletion (or mutation) on A $\beta$ aggregation. Firstly, the higher internal stability of the mutant oligomers increases the rate of oligomer formation and stability (thick arrow). Secondly, the altered dynamics and surface properties hamper fibril formation (black cross), thus additionally contributing to the enrichment of oligomers (see text for details). These oligomers trigger a cascade of events leading to Alzheimer's disease 
(a)

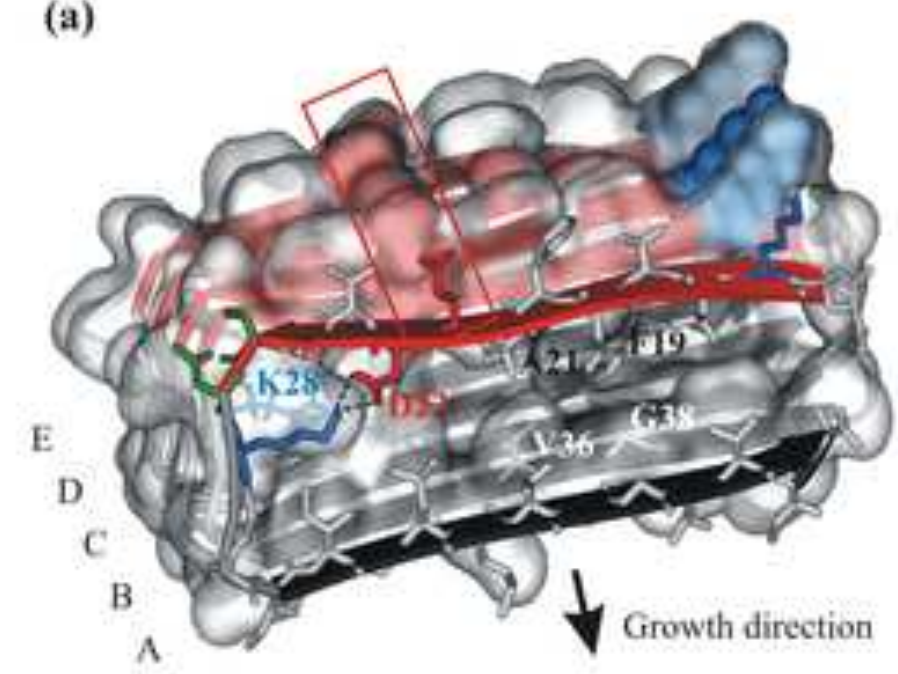

(c)

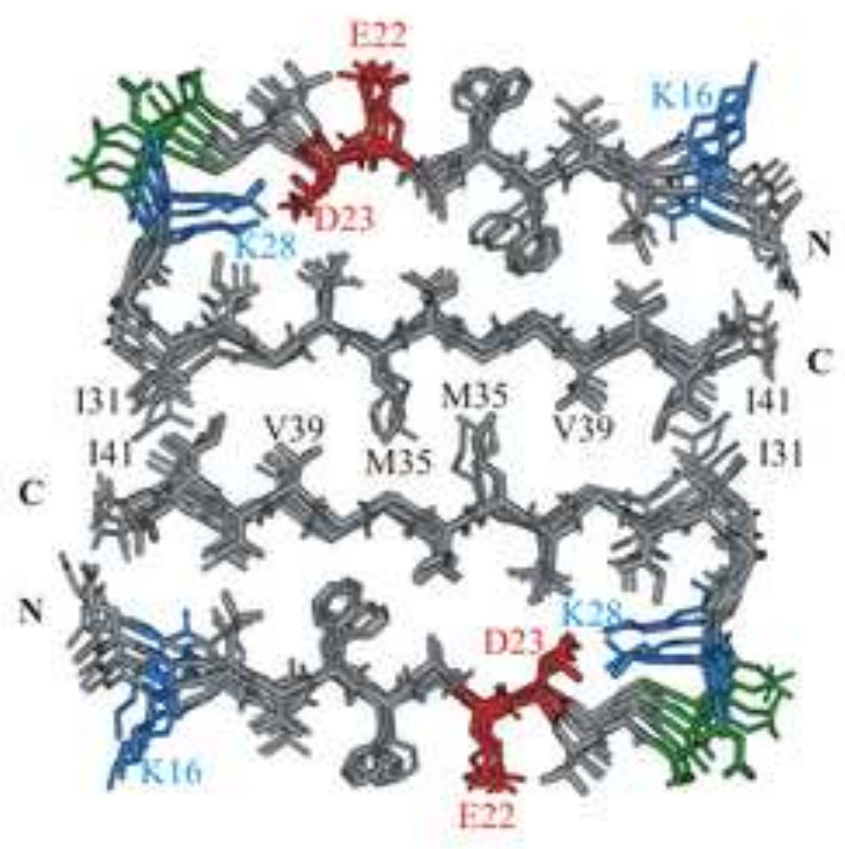

(b)

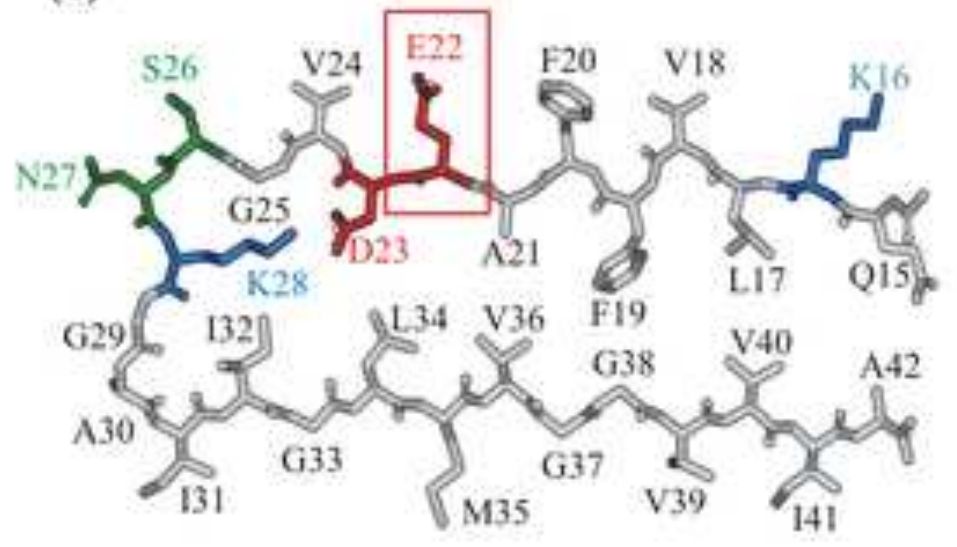

(d)

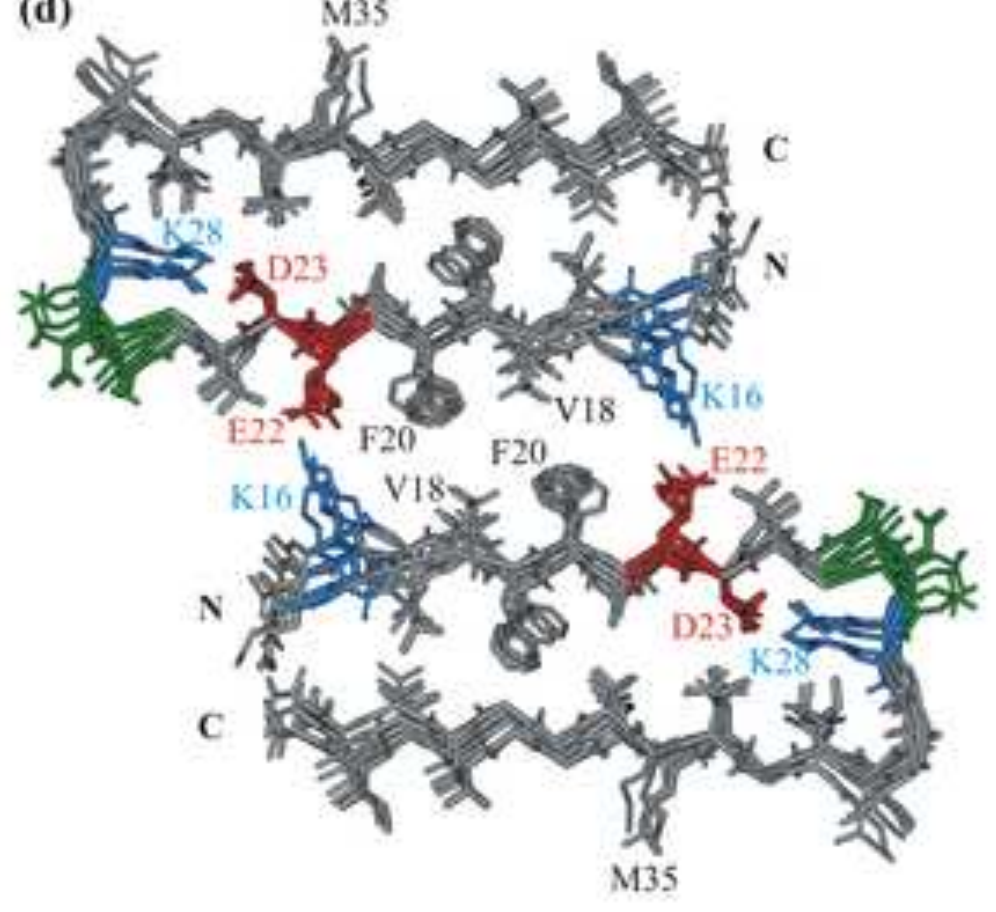




\section{Figure 2

Click here to download high resolution image

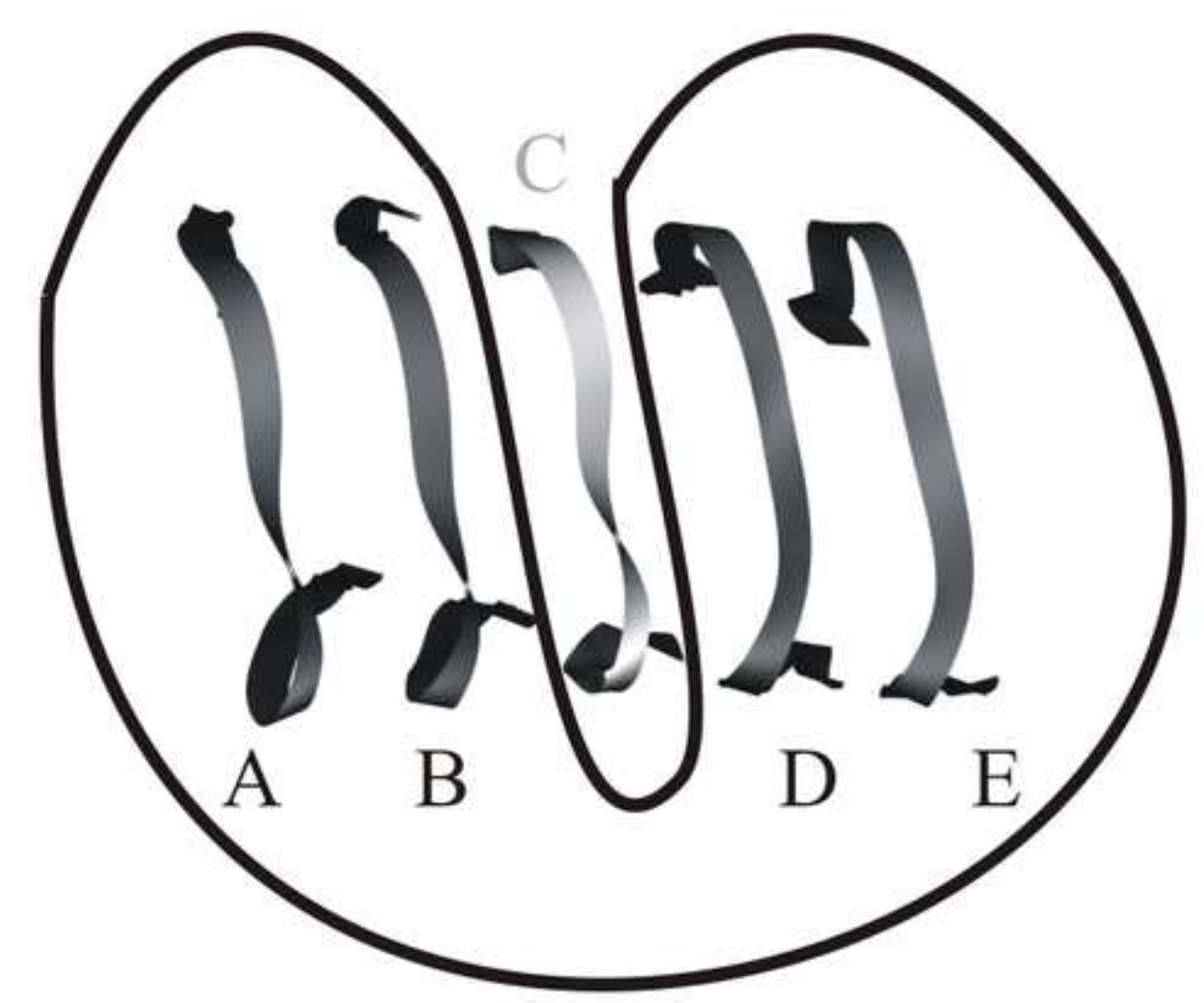




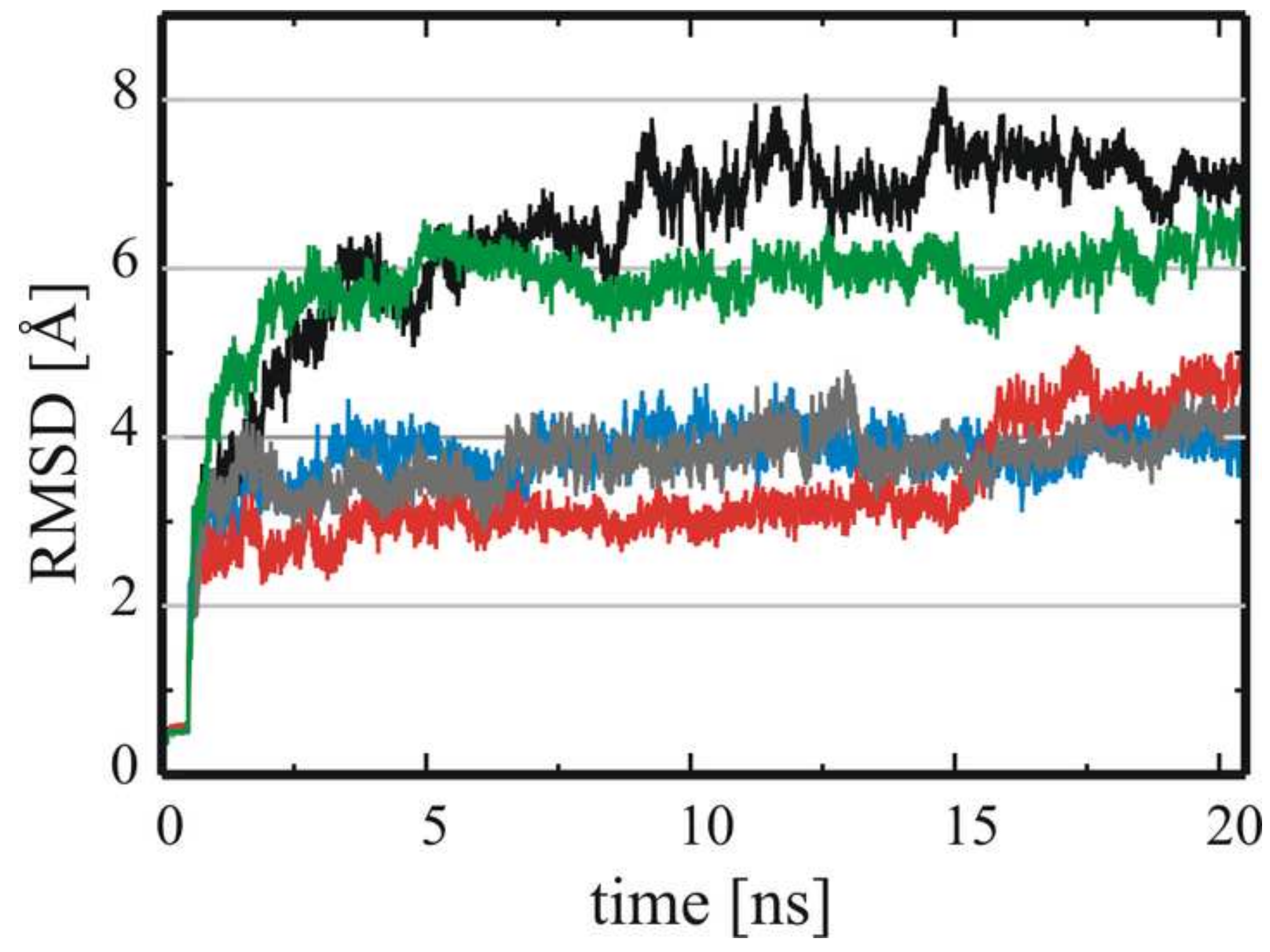


Click here to download high resolution image
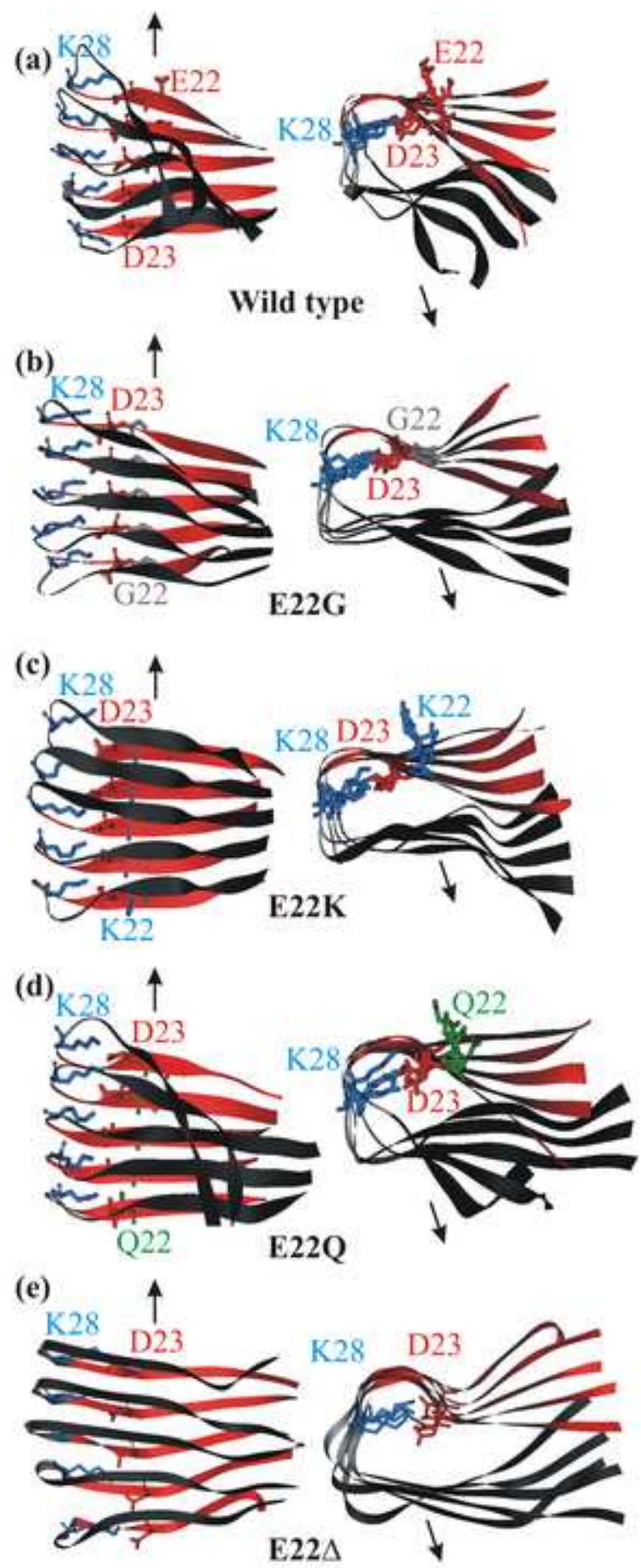

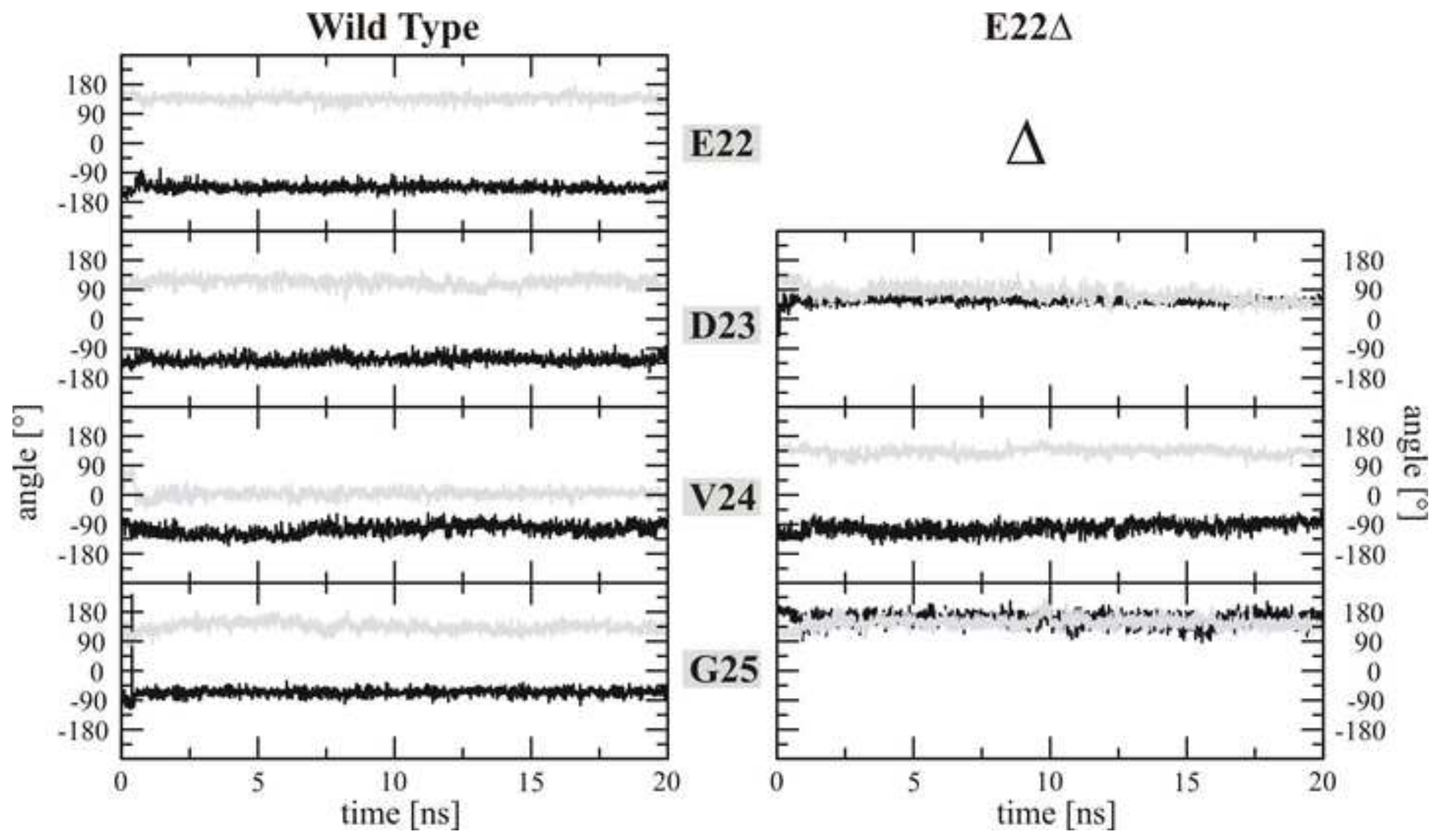
(a)

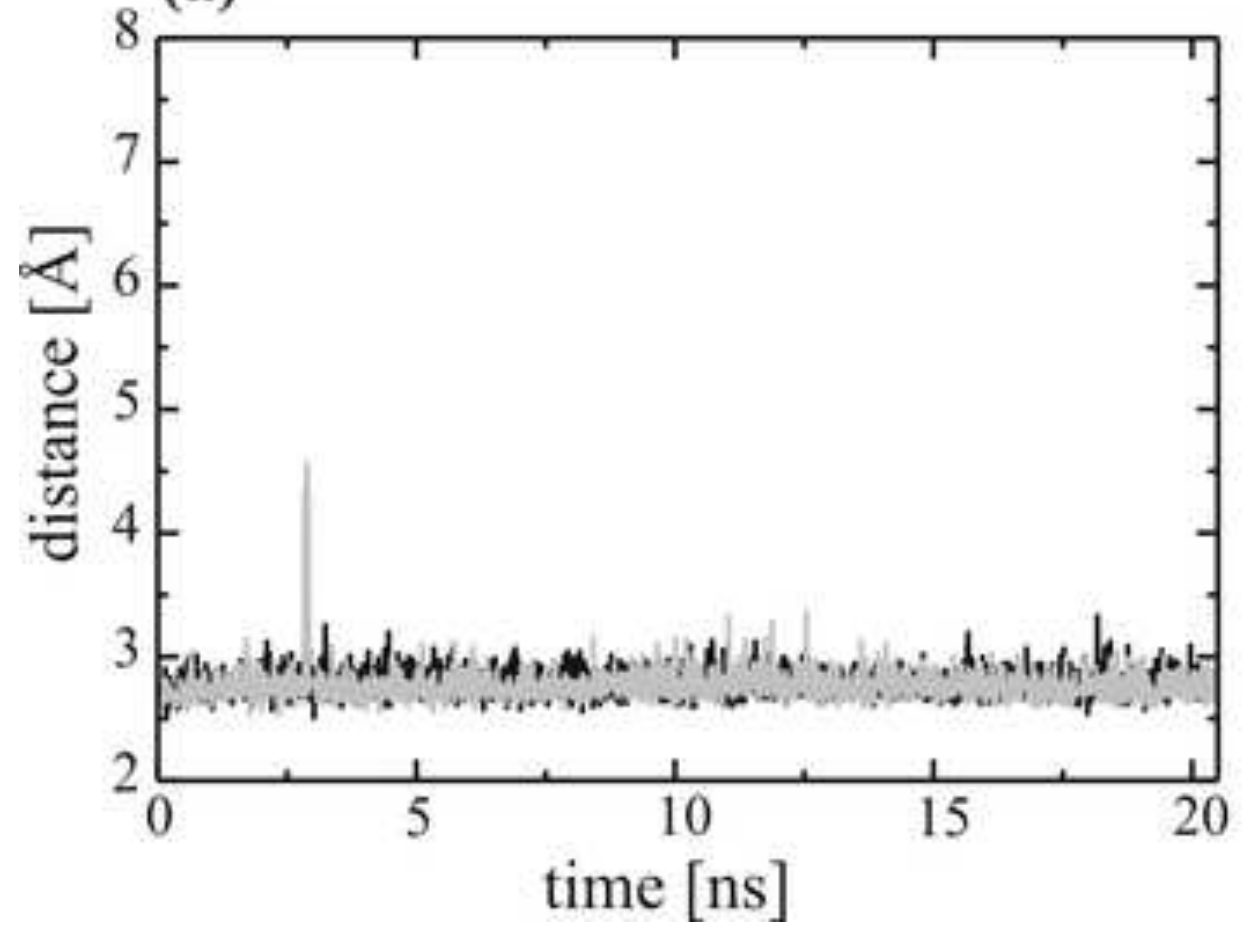

(b)

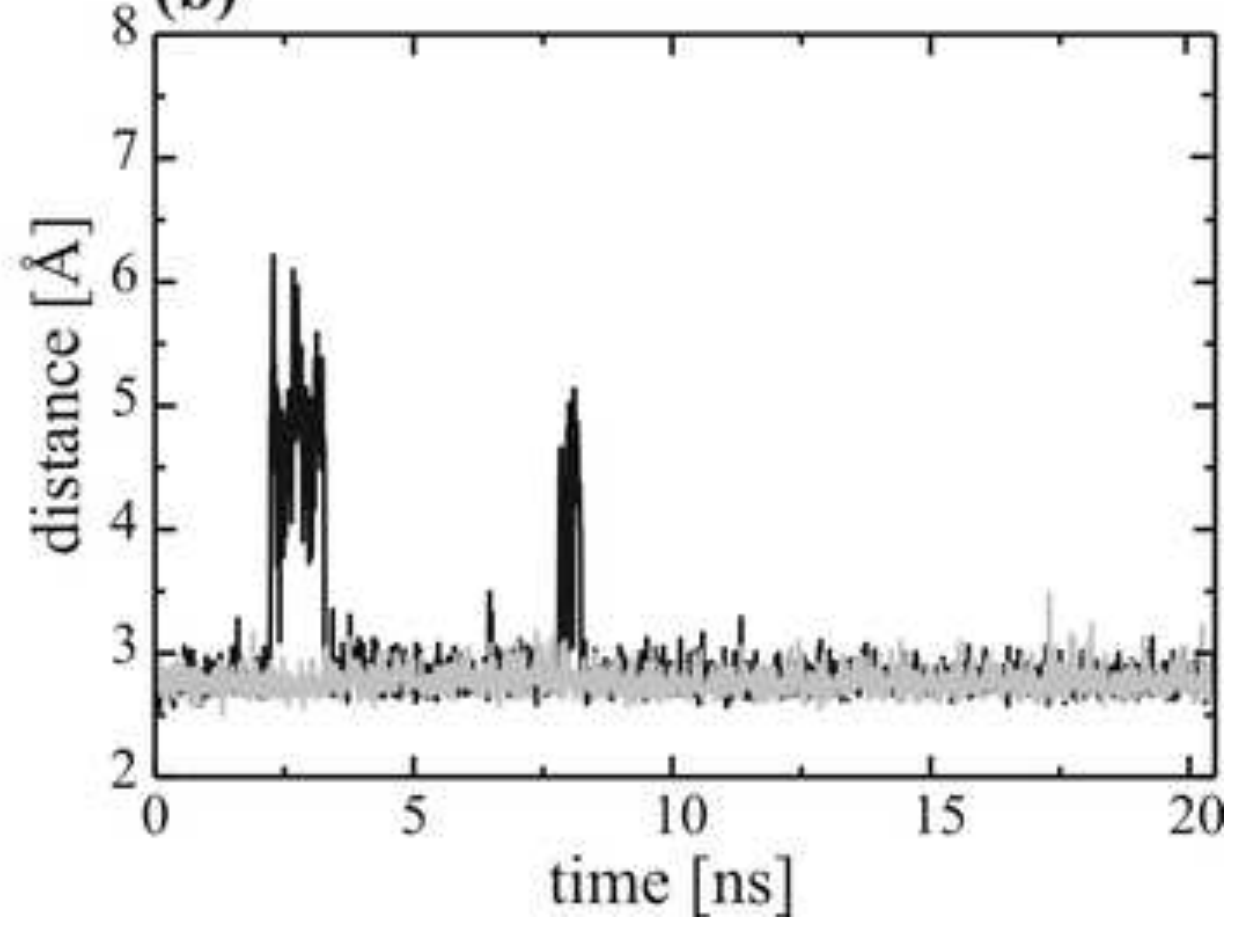


Click here to download high resolution image

(a)

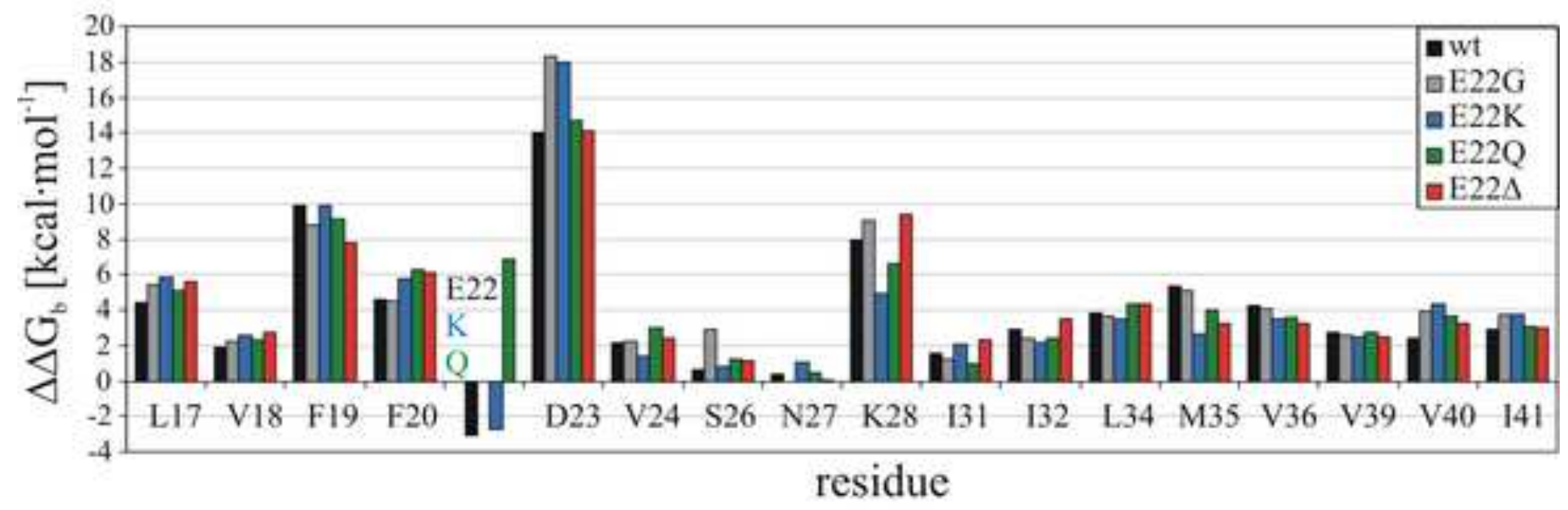

(b)

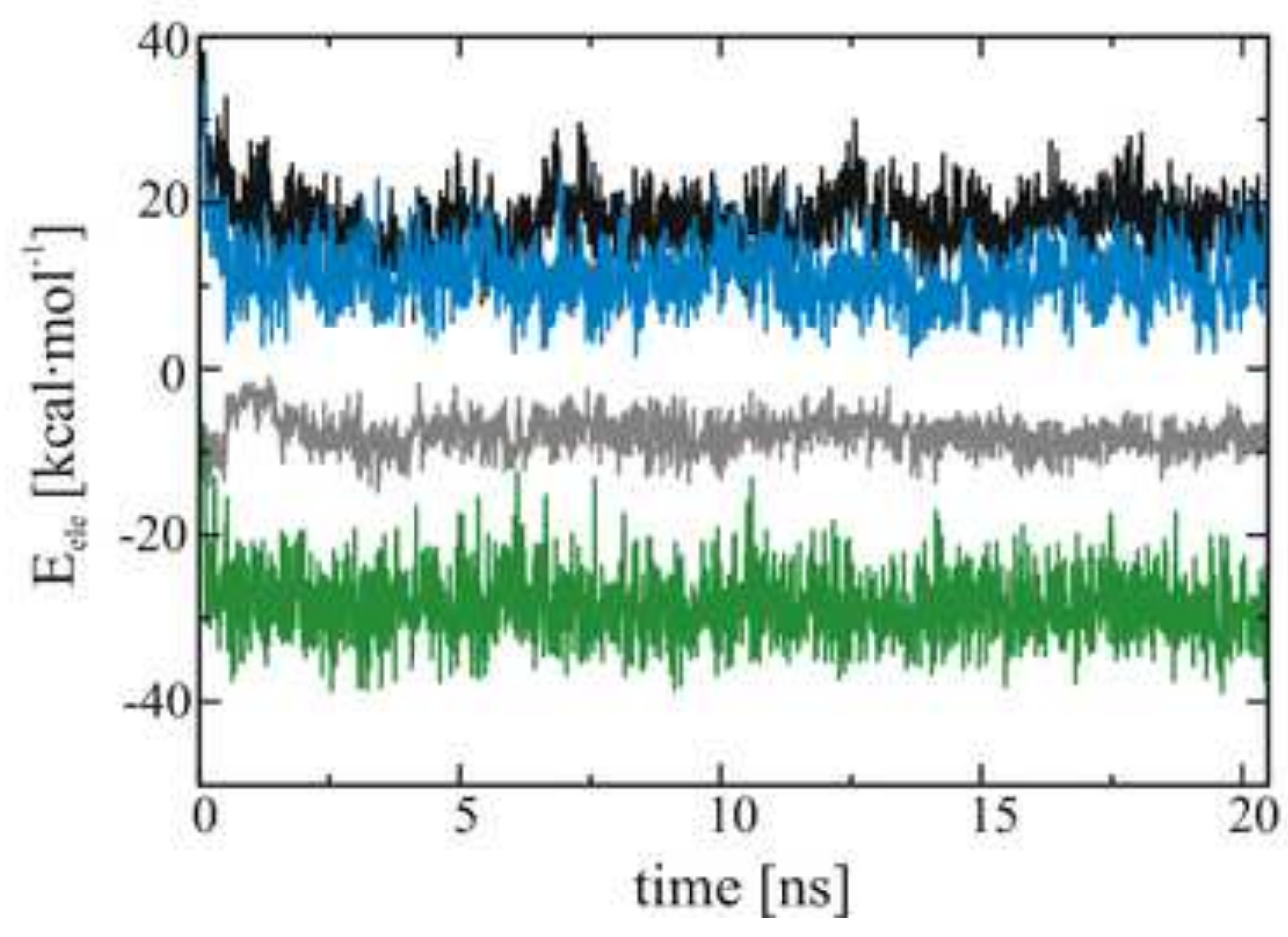




\title{
$\left[\mathrm{E} 22 \Delta-\mathrm{A} \beta_{\text {monomer }}\right] \rightleftarrows\left[\mathrm{E} 22 \Delta-\mathrm{A} \beta_{\text {olig }}\right] \not[\mathrm{E} 22 \Delta-\mathrm{A} \beta]_{\text {fibril }}$
}

Modulation of receptor function

or

Formation of ion channels in neuronal membranes

$\downarrow$

Disruption of synaptic function

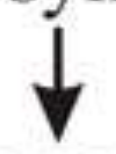

Progressive neuronal injury

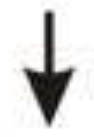

Neuronal dysfunction \& cell death

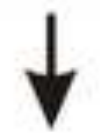

\author{
Alzheimer's disease
}

